\title{
Bazı Meteorolojik Verilerin Mekânsal Değişkenliği Üzerine Bir Karşılaştırma: Kahramanmaraş Örneği
}

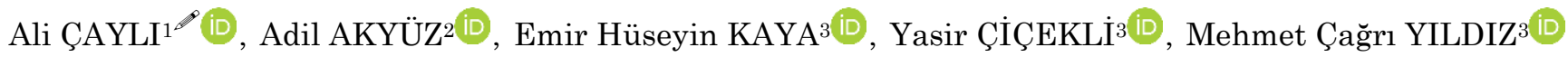 \\ ${ }^{1}$ Kahramanmaraş Sütçü İmam Üniversitesi, Türkoğlu Meslek Yüksekokulu, Kahramanmaraş, ${ }^{2}$ Kahramanmaraş Sütçü İmam \\ Üniversitesi, Ziraat Fakültesi, Kahramanmaraş, ${ }^{3}$ Kahramanmaraş Sütçü İmam Üniversitesi, Fen Bilimleri Enstitüsü, \\ Kahramanmaraş
}

$\triangle$ : alicayli@ksu.edu.tr

\section{ÖZET}

Tarımsal üretimi etkileyen en önemli parametre çevre koşullarıdır. Uygun iklim koşullarının sağlanması ve bu koşulların takip edilmesi, birçok tarımsal yapıda ve üretim sistemlerinde hayati önem arz etmektedir. Ancak meteoroloji istasyonlarından elde edilen veriler çok geniş alanlar için kullanılmaktadır. Bu durum yapılan hassas hesaplamalarda ve analizlerde doğru sonuçlar elde edilememesine neden olmaktadır. Bu sebeple çalışmada, bölgesel olarak büyük farklılıklar gösterebilen sıcaklık ve oransal nem değerlerinin il bazındaki değişimi araştırılmıştır. Bu amaçla, Kahramanmaraş merkez ilçe sinırları içerisindeki Merkez Meteoroloji İstasyonu verileri ile istasyona $10 \mathrm{~km}$ uzaklıkta bulunan araştırma arazisinde ölçülen sıcaklık ve oransal nem verileri ayrıca il merkezinde bulunan Havalimanı Meteoroloji İstasyon verileri istatistiksel olarak karşılaştırılmıştır.

Elde edilen bulgular, rakımı $468 \mathrm{~m}$ olan araştırma arazisi ile Merkez Meteoroloji İstasyonu verileri arasında günlük ortalama sıcaklıklarda farklılık olmadığ sicakliklar ile ortalama, maksimum ve minimum oransal nem değerleri arasındaki farkın önemli olduğunu göstermiştir $(\mathrm{P}<0.05)$. Ayrıca rakımı $572 \mathrm{~m}$ olan Merkez Meteoroloji İstasyonu ile rakımı $525 \mathrm{~m}$ olan Havalimanı Meteoroloji İstasyonu verileri arasında yapılan karşılaştırma ise günlük minimum sıcaklıklar, oransal nem ve rüzgâr hızı verileri arasında istatistiksel olarak farklılıklar olduğunu görülmektedir $(\mathrm{P}<0.001)$. Günlük ortalama sıcaklıklar arasında ise yıllık bazda farklılık bulunmamasına rağmen Kasım, Aralık ve Nisan ayları için farklılık olduğu bulunmuştur $(\mathrm{P}<0.05)$.
DOI:10.18016/ksudobil.320511

\author{
Makale Tarihçesi \\ Geliş : 12.06 .2017 \\ Kabul : 02.08.2017
}

Anahtar Kelimeler

Çevre koşulları,

Mekânsal iklim verileri,

Veri kaydedici

\section{Araştırma Makalesi}

\section{A Comparison on The Spatial Variability of Some Meteorological Data: Kahramanmaras Case Study}

\section{ABSTRACT}

The most important parameter affecting agricultural production is environmental conditions. Providing suitable climatic conditions and monitoring these conditions is of vital importance in many agricultural structures and production systems. However, data obtained from official meteorological stations are used for very large areas. Such cases may lead to inaccurate results in the calculations. For this reason, the provincial variation of temperature and relative humidity values, which may have regional differences, were investigated. For this purpose, the temperature and the relative humidity data measured in the survey area located $10 \mathrm{~km}$ away from the station and the data of the official meteorological station at the airport in the city center of the province were statistically compared with those of the official meteorological station data in the Kahramanmaras central district borders.

\section{Article History}

Received: 12.06.2017

Accepted: 02.08.2017

\section{Keywords \\ Environmental conditions, \\ Spatial climate data, \\ Data logger}

Research Article 
The findings showed that the differences between the maximum and minimum temperatures and the mean, maximum and minimum relative humidity values were significant, although there were no differences in the mean daily temperatures between the study site (altitude $468 \mathrm{~m}$ ) and the central meteorological station (altitude 572 $\mathrm{m})$ data. Also statistically significant differences were found between the Central Station and the Airport Station daily minimum temperature, relative humidity and wind speed data $(\mathrm{P}<0.001)$. Daily mean temperatures were found to be different for November, December and April even though there was no difference on an annual basis $(\mathrm{P}<0.05)$.

To Cited : Çaylı A, Akyüz A, Kaya EH, Çiçekli Y, Yıldız MÇ 2018. Bazı Meteorolojik Verilerin Mekânsal Değişkenliği Üzerine Bir Karşlaş̧tırma: Kahramanmaraş Örneği. KSÜ Tarim ve Doğa Derg 21(2): 175-184, DOI:10.18016/ksudobil.320511.

\section{GİRIŞ}

Tarımsal faaliyetler için yapılan modelleme çalışmaları ve hesaplamalarda kullanılan verilerin tam olarak faaliyetlerin yürütüldüğü alanı temsil etmesi modelin başarısı ve hesaplamaların doğruluğu için oldukça önemlidir. Ancak çoğu zaman bu hesaplamalar bölgede bulunan resmi meteoroloji istasyonlarından temin edilen veriler ile yapılmaktadır. Bölge bazında alınan bu veriler, alan bazında yapılacak çalışmaları tam olarak temsil edemeyebilir.

Matematiksel modellerin potansiyeli, doğal sistemlerin etkileşimlerini ve bileşenleri incelemek, sonuçlar üzerindeki değişiklik ve belirsizlikleri tahmin etmek ve farklı geçmişlere sahip bilim adamları, yöneticiler ve topluluklar arasındaki iletişimin teşvik edilmesi için yaygın olarak kabul görmektedir (Bellocchi ve ark., 2010).

Tarımsal uygulamalarda önemli bir parametre olan iklim verileri içerisinde bitki büyüme modeli için ayrı ayrı iklim parametreleri incelendiğinde sıcaklık, ölçüm hatalarına karşı çok hassastır (Fodor ve Kovacs, 2005).

Bitkiler ekimden sonra gelişme ve hasat dönemine kadar farklı seviyedeki sicaklıklara maruz kalırlar. Zira ekimden sonra çimlenme döneminde toprak sıcaklığı önemlidir. Daha sonraki dönemlerde ise zeminden itibaren artan yüksekliklerdeki sıcaklıklara maruz kalırlar (Swan ve ark., 1987; Jamieson ve ark., 1995). Bu durum genellikle modelleme çalışmalarında ve hesaplamalarda dikkate alınmamaktadır. Bu sebeple yapılacak tahminler doğru sonuç vermeyebilir. Bitkisel üretim benzetim çalışmalarında belirsizlikler üzerinde verilerin mekânsal çözünürlüğünün önemli etkisi bulunmaktadır (Mearns ve ark., 2001; Zhao ve ark., 2015). Kim ve Yoo (2015) farklı çözünürlükteki iklim verileri ile yaptıkları bitki verim benzetimi çalışmasında yüksek çözünürlüklü verilerde $(1.0 \mathrm{~km})$ bitki verim benzetimi belirsizliğinin, düşük çözünürlükteki verilere göre $(12.5 \mathrm{~km})$ daha düşük olduğunu bildirmektedir. Monestiez ve ark. (2001)'e göre modellemede kullanılan sıcaklık değerlerindeki $\pm 2{ }^{\circ} \mathrm{C}^{\prime}$ lik fark, sulanan mısır kültürü hasat tarihinde 18-28 gün, verimde ise $2.8 \mathrm{t} / \mathrm{ha}$ sapma oluşturmaktadır.

Tarımsal faaliyetler sonucu elde edilecek ürün miktar ve kalitesi çevre koşullarına doğrudan bağlıdır. Bitkilerin ekim-dikim ve hasat dönemleri yöreye göre farklllıklar göstermektedir. Bitkilerin büyüme ve büyüme öncesinde çeşitli tepkileri ve bunların belirlenmesi ile ilgili çalışmalarda kullanılacak veriler için yapılacak ölçümlerin, hesaplamanın yapılacağı alanın yakınında olmasi gerekmektedir (Bonhomme, 2000).

Hidroloji ve su kaynakları yönetimi uygulamaları için gerekli meteorolojik değişkenler genellikle meteorolojik istasyonlarda ölçülür ve veriler yalnızca ölçüm noktasında geçerlidir. Mekânsal enterpolasyon yöntemleri, diğer yerlerde meteorolojik değişkenleri tahmin etmek için kullanılabilir (Apaydin ve ark., 2004). Özellikle kutup-yörüngeli uydulardan uzaktan algılama yöntemi ile elde edilen veriler, bitki örtüsü olan yüzeyler üzerinde zamansal ve mekânsal olarak sürekli bilgi sağlar ve albedo, biyom tipi ve yaprak alanı endeksi gibi yüzey biyofiziksel değişkenleri doğru bir şekilde parametreleştirmek için kullanışlıdır (Los ve ark., 2000). Küresel ETyi (Evapotranspirasyon) tahmin etmek için sağlam bir algoritma geliştirmek önemli bir çalışma gerektirir. ET"nin geleneksel enerji denge modelleri, birçoğu küresel olarak belirlenmesi zor olan çok sayıda fiziksel parametrenin açık şekilde karakterize edilmesini gerektirir (Mu ve ark., 2007).

Özellikle bitki su tüketimi ve sulama çalışmalarında önemli bir parametre olan evapotranspirasyonu etkileyen faktörlerin başında güneş radyasyonu, sıcaklık, oransal nem ve rüzgâr hızı gelmektedir (Monteith, 1965). Evapotranspirasyonun doğru tahmin edilmesi etkili bir sulama planlaması için önemlidir (Moorhead ve ark., 2016).

Seralarda isitma ihtiyaci belirlenmesi ve isitma sisteminin projelenmesi için geçmiş yıllarda gerçekleşen minimum sıcaklık ortalama değerleri kullanılmaktadır. $\mathrm{Bu}$ hesaplamalarda iç-dış ortam sıcaklığındaki her 1 ${ }^{\circ} \mathrm{C}$ 'lik değişim $(\Delta \mathrm{t})$, enerji gereksiniminde \%10'luk bir fark oluşturmaktadır. Bitki büyümesinin farklı aşamalarında optimum bir ortam sağlamak için sera mikro klimasının modellenmesi çok önemlidir. Doğru bir termal model geliştirmek, güneş radyasyonu girişinin hesaplanması ve toplam ısı iletim katsayısı sera enerji ve kütle dengesi açısından önemlidir (Sethi ve ark., 2013). Ayrıca optimum bitki yetişme koşullarının sağlanması 
için sıcaklık ve nem gibi çevresel iklim parametreleri sürekli olarak izlenmelidir (Mesas-Carrascosa ve ark., 2015).

Günümüzde modern günlük yaşamın bir çok alanında karşımıza çıkan, özellikle kablosuz sensor ağı teknolojileri ile yapılan ölçümler sonucu elde edilen veriler, kentsel çevreden, doğal kaynaklar ve hassas ekolojilere kadar bir çok alanda çevresel göstergelerin anlaşılmasını olanaklı kılmaktadır (Gubbi ve ark., 2013). Yoksul kırsal alanlarda çevre yönetimi ve tarım politikalarının izlenmesini ve tarımsal üretimi geliştirmek için bu teknolojiler yeni olanaklar sunmaktadır (Mesas-Carrascosa ve ark., 2015). Veri toplama sistemlerinin düşük maliyet ile temin edilebilmesi daha yüksek çözünürlükte (daha dar alanlardan) sicaklık ve oransal nem gibi iklim parametresi verilerinin toplanmasını kolaylaştırmıştır. $\mathrm{Bu}$ amaçla geliştirilen ve güvenli bir şekilde veri toplanabilen yeni nesil cihazlar tarımsal amaçlı kullanılmaktadır. Ayrıca elektronik teknolojilerindeki hızlı gelişmeler, çeşitli ucuz algılama, izleme ve kontrol sistemlerinden faydalanılabilmesini olanaklı hale getirmiştir (Fisher ve Sui, 2013). Bu gelişmeler sensör boyutlarının küçülmesi ile daha yetenekli, çevresiyle iletişim kurabilen düşük maliyetli cihazların kullanımını yaygınlaştırmaktadır. Piyasada çok sayıda firma tarafindan veri toplama amaciyla üretilen ticari ürünler bulunmaktadır.

Kahramanmaraş'ta tarımsal faaliyetlerin yaygın bir şekilde yürütüldüğü bölge ile şehir merkezinde bulunan Merkez Meteoroloji İstasyonu bölgesi arasında önemli bir iklimsel farklılık olabilir. $\mathrm{Bu}$ farklılık, evapotranspirasyon, bitki büyüme modeli, sera isı enerjisi ihtiyacının belirlenmesi, tarımsal yapılarda havalandırma ve serinletme sistemlerinin projelenmesi gibi bazı hesaplamalarda hatalara neden olabilir.

$\mathrm{Bu}$ çalışmada, Kahramanmaraş Merkez Meteoroloji İstasyon verileri ile araştırma alanındaki veriler karşlaştırılmıştır. Ayrıca il merkezinde bulunan Havalimanı, geniş tarım arazilerine yakın olması nedeniyle Kahramanmaraş'ta tarım yapılan bölgeyi temsil edebilecek bir konumdadır. Bu sebeple Merkez Meteoroloji İstasyonu verileri ile Havalimanı Meteoroloji İstasyonu verileri de istatistiksel olarak karşılaştırılmıştır.

\section{MATERYAL ve METOT}

Araştırma, deniz seviyesinden $468 \mathrm{~m}$ yükseklikte bulunan Kahramanmaraş Sütçü İmam Üniversitesi araştırma alanında $\left(37^{\circ} 35^{\prime} 20^{\prime \prime} \mathrm{K}, 36^{\circ} 48^{\prime} 12^{\prime \prime} \mathrm{D}\right.$, WGS84) Mart 2016 - Nisan 2016 dönemlerinde yürütülmüştür (Şekil 1). Bölge tipik olarak Akdeniz iklimi etkisi altında bulunmaktadır. İklim verilerinin ölçülmesinde yerden 2 m yükseklikteki iklim siperi içerisine yerleştirilen, TFA Nexus meteoroloji istasyonu cihazı kullanılmıştır. $\mathrm{Bu}$ cihaz, sıcaklık ölçümünü $-40{ }^{\circ} \mathrm{C}$ ile $80^{\circ} \mathrm{C}$ arasında $\pm 1{ }^{\circ} \mathrm{C}$ doğrulukta ve $0.1{ }^{\circ} \mathrm{C}$ hassasiyette, oransal nem ölçümünü ise $\% 0$ ile $\% 99$ arasında $\pm \% 5$ doğrulukta ve $\% 1$ hassasiyette yapmaktadır.

Cihazın ölçüm doğruluğunun belirlenmesi için, bir çok bilimsel araştırmada güvenle kullanılan (Gallagher ve ark., 2010; Romanovsky ve ark., 2010; He ve ark., 2012; Dikmen ve ark., 2013; Tan ve ark., 2013; Johansson ve ark., 2015) HOBO U12 veri kaydedici cihaz referans olarak kullanılarak kalibrasyonu kontrol edilmiştir. Bu amaçla 10 dakika aralıkla $20 \mathrm{kez}$ sıcaklık ve oransal nem değerleri kaydedilmiş ve hesaplanan maksimum oransal hata miktarı \%1.84 olarak bulunmuştur.

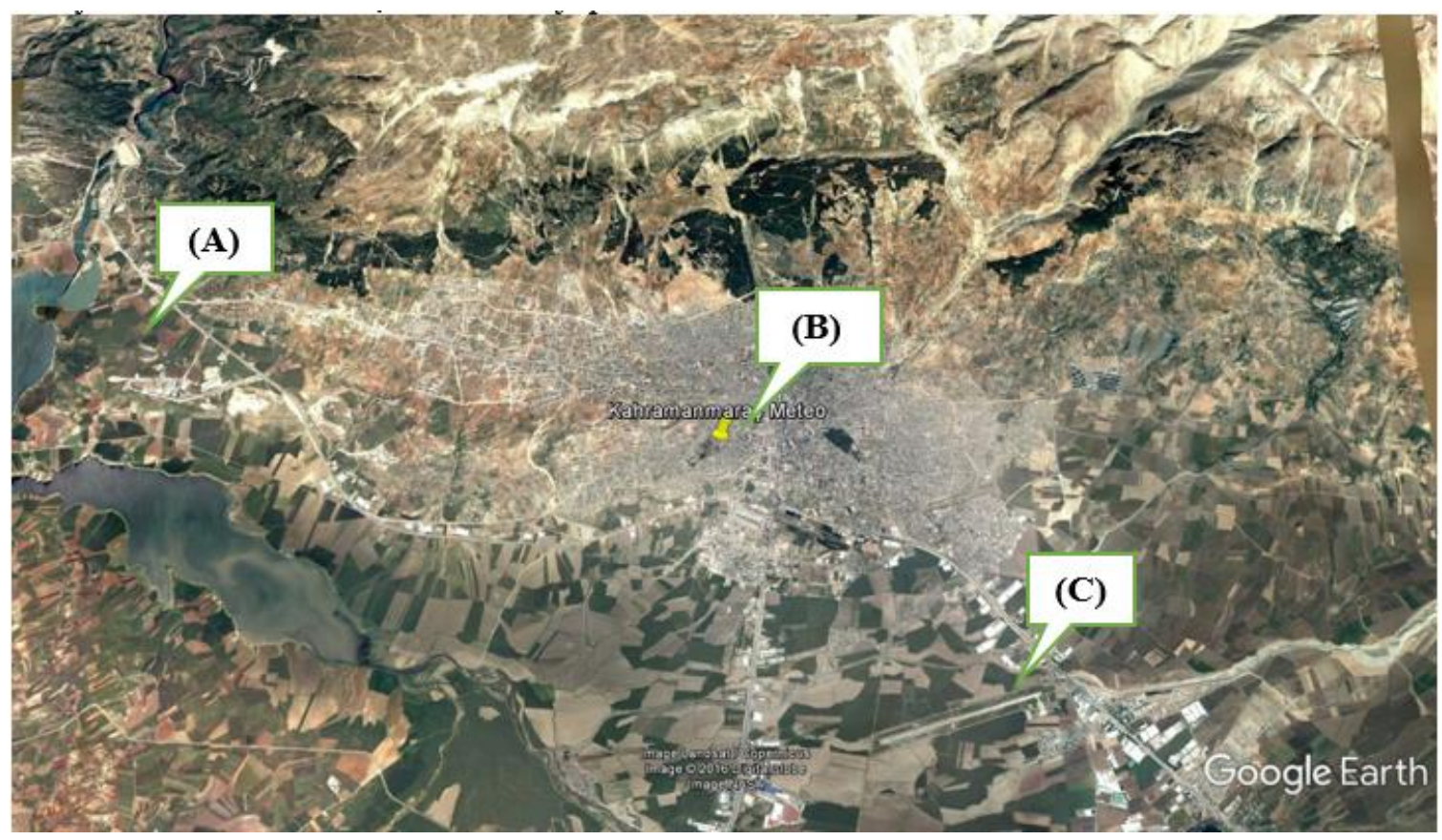

Şekil 1. Çalışmadaki verilerinin alındığı yerler (A) K.S.Ü. araştırma arazisi (B) Kahramanmaraş meteoroloji istasyonu (C) Havalimanı meteoroloji istasyonu 
Ölçüm verilerinden saatlik ortalama ve günlük ortalama değerler Eşitlik 1'e göre hesaplanmıştır.

$X o r t=\frac{\sum_{i=1}^{n} X i}{n}$

Eşitlikte Xort: saatlik ortalama, X: ölçüm değeri, n:ölçüm sayısını göstermektedir.

Araştırmada il merkezindeki iki farklı bölge için alınan veriler, Meteoroloji Genel Müdürlügünden temin edilen Kahramanmaraş Merkez Meteoroloji istasyonu verileri ile karşlaş̧ırılmıştır. Bunlardan ilkinde araştırma alanından 25 Mart - 25 Nisan 2016 tarihleri arasında her 5 dakikada bir ölçülen değerlerden hesaplanan günlük ortalamalar ile araştırma alanına $10 \mathrm{~km}$ mesafedeki Merkez Meteoroloji İstasyonu verileri karşılaştırılmıştır. İkincisinde ise 2015 yılı için Kahramanmaraş Havalimanında bulunan ve denizden yüksekliği $525 \mathrm{~m}$ olan Havalimanı Meteoroloji İstasyonu verileri ile denizden yüksekliği 572 m Merkez Meteoroloji İstasyonu verileri karşılaş̧ırılmıştır.

Veriler karşılaştırılması için, ortalama mutlak hata (MAE) Eşitlik 2'ye, ortalama mutlak yüzde hata (MAPE) Eşitlik 3'e, ortalama hata kareleri (MSE) Eşitlik 4'e, ortalama hata kareleri karekökü (RMSE) ise Eşitlik 5'e göre hesaplanmıştır.

$M A E=\frac{1}{n} \sum_{i=1}^{n}\left|X_{\text {istasyonc }, i}-X_{\text {istasyonB }, i}\right|$

$$
\begin{aligned}
& \text { MAPE } \frac{1}{n} \sum_{i=1}^{n}\left|\frac{X_{\text {istasyonc }, i}-X_{\text {istasyon }, i} \mid}{X_{\text {istasyonC }, i}}\right| 100 \\
& M S E=\frac{\sum_{i=1}^{n}\left(X_{\text {istasyonC }, i}-X_{\text {istasyon }, i}\right)^{2}}{n} \\
& \text { RMSE }=\sqrt{\frac{\sum_{i=1}^{n}\left(X_{\text {istasyonc }, i}-X_{\text {istasyon }, i}\right)^{2}}{n}}
\end{aligned}
$$

Eşitlikte; n gözlem sayısı, XistasyonC (C) istasyonu ölçüm değeri, XistasyonB (B) istasyonu ölçüm değeridir.

Ayrıca iki grubun ortalamaları arasındaki farkın anlamlı olup olmadığının karşılaştırılması için SPSS 22 istatistik programı kullanılarak $\mathrm{T}$ testi (bağımsız örneklem) yapılmıştır.

\section{BULGULAR ve TARTIŞMA}

Araştırma alanında 30 gün boyunca her 5 dakikada bir iklim verileri veri tabanına kaydedilmiş ve saatlik ortalama değerler Eşitlik 1'e göre hesaplanmıştır. Saatlik ortalama hava sıcaklığı değerleri Şekil 2a'da, hava oransal nemi değerleri Şekil 2b'de verilmiştir. Şekiller incelendiğinde veri alınan süre boyunca sistemin veri ölçme ve kaydetme işlemlerinde herhangi bir kesinti olmadığı anlaşılmaktadır.

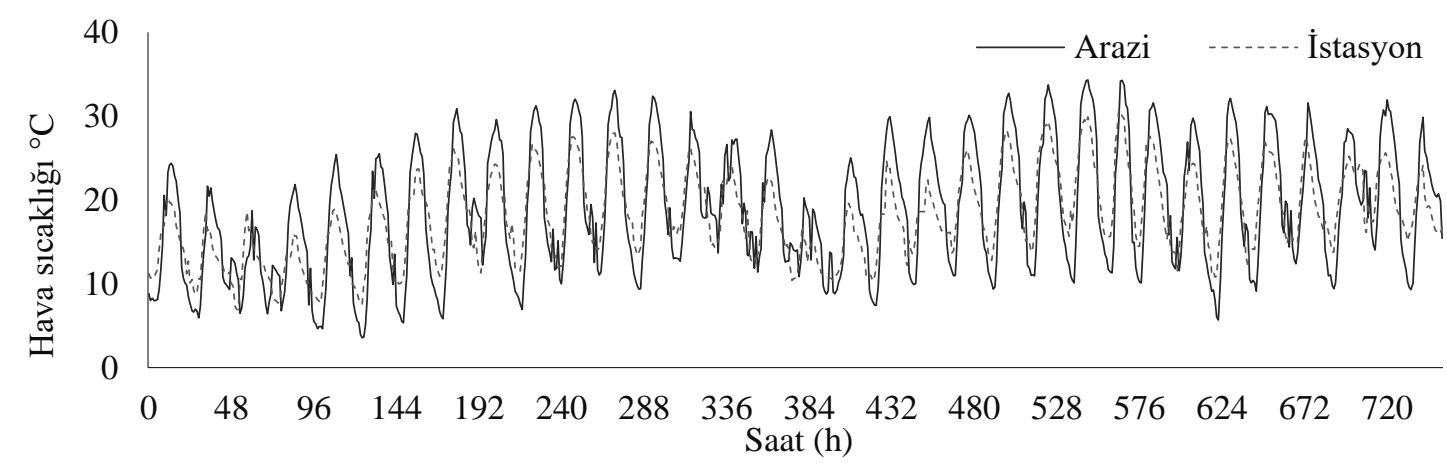

(a)

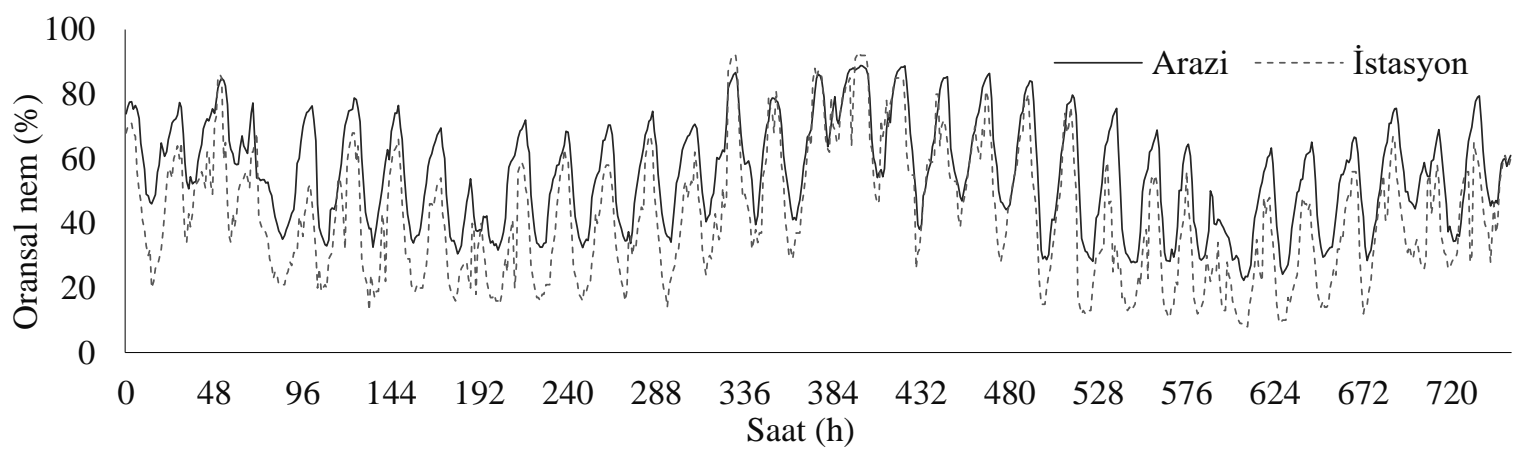

(b)

Şekil 2. Saatlik ortalama değerler, (a) sıcaklık (b) oransal nem 
Ayrıca maksimum ve minimum değerlerde farklılıklar olmasına rağmen genel olarak grafiğin senkronize olarak oluştuğu görülmektedir. Şekil 2b'de verilen saatlik oransal nem grafiğinde Merkez Meteoroloji İstasyonu minimum değerlerinin arazi ölçüm değerinden genellikle düşük olduğu görülmektedir. $\mathrm{Bu}$ durum, araştırma arazisinin hemen yakınında bulunan baraj gölünün etkisinden kaynaklanmış olabilir. Araştırma arazisinde oransal nem, yaklaşı $10 \mathrm{~km}$ mesafede ve deniz seviyesinden yüksekliği $572 \mathrm{~m}$ olan Merkez Meteoroloji İstasyonunda ölçülenden daha yüksek olduğu görülmektedir.

Araştırma arazisi ve Merkez Meteoroloji İstasyonundan alınan verilerin saatlik ortalaması arasındaki fark, sıcaklık için $3.84{ }^{\circ} \mathrm{C}$, RMSE $4.13^{\circ} \mathrm{C}$, oransal nem saatlik ortalaması arasındaki fark \%7.34 ve RMSE \%16.18 olarak bulunmuştur. $\mathrm{Bu}$ verilerin arasındaki ilişkinin belirlenmesi amacıyla yapılan $\mathrm{T}$ testine göre sicaklık ve oransal nem saatlik ortalamaları arasındaki fark istatistiksel olarak önemli bulunmuştur $(\mathrm{P}<0.05)$.

Aynı zamanda bu verilerin günlük ortalama (Şekil 3a, Şekil 3b), maksimum (SSekil 3c, Şekil 3d) ve minimum (Şekil 3e, Şekil 3f) değerleri arasındaki ilişkilerde araştırılmıştır. Ortalamalar arasındaki farklar ve RMSE değerleri Tablo 1'de verilmiştir. Tablo 1 incelendiğinde ortalama sıcaklıklar arasındaki farkın düşük olmasına karşın maksimum ve minimum sıcaklıklar arasındaki farkların yüksek olduğu görülmektedir.

Tablo 1. Kahramanmaraş Merkez Meteoroloji İstasyonu ile araştırma arazisi iklim değerleri arasındaki istatistiksel ilişkiler (25 Mart - 25 Nisan 2016)

\begin{tabular}{lcc}
\hline \multicolumn{1}{c}{ Veri } & MAE & RMSE \\
\hline Ortalama sicaklık $\left({ }^{\circ} \mathrm{C}\right)$ & 0.59 & 1.28 \\
Maksimum sıcaklık $\left({ }^{\circ} \mathrm{C}\right)$ & 4.56 & 4.72 \\
Minimum sıcaklık $\left({ }^{\circ} \mathrm{C}\right)$ & 3.16 & 3.52 \\
Ortalama oransal nem (\%) & 13.29 & 14.22 \\
Maksimum oransal nem (\%) & 8.68 & 11.64 \\
Minimum oransal nem (\%) & 14.99 & 15.62 \\
\hline
\end{tabular}

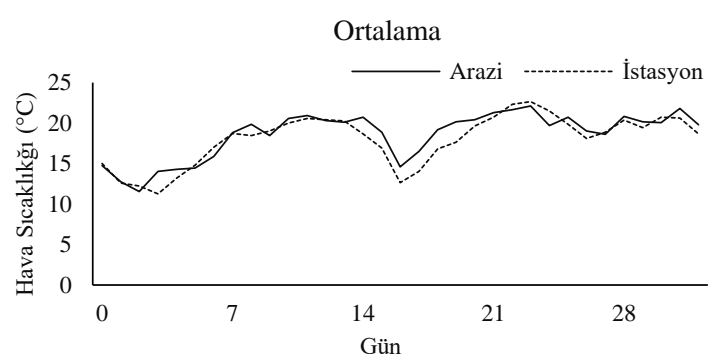

(a)

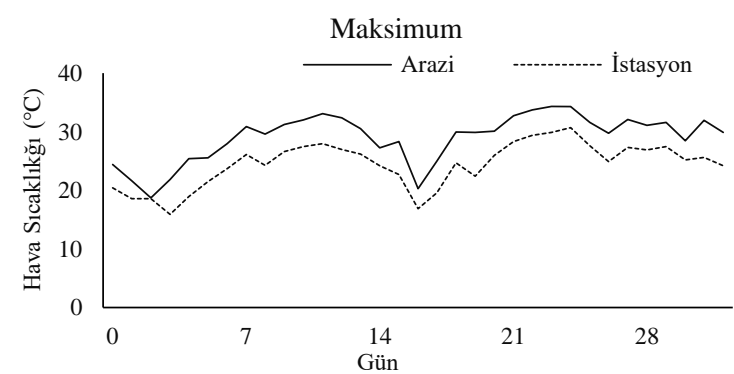

(c)

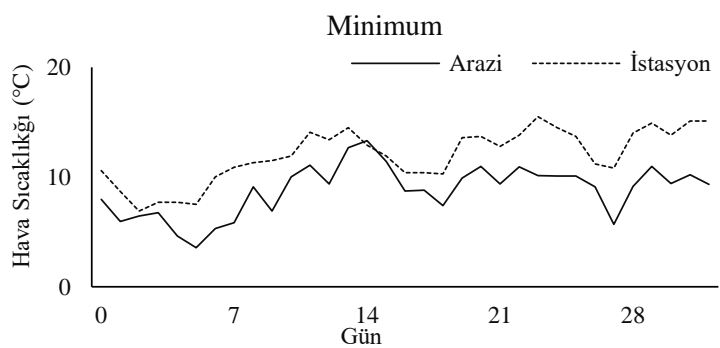

(e)

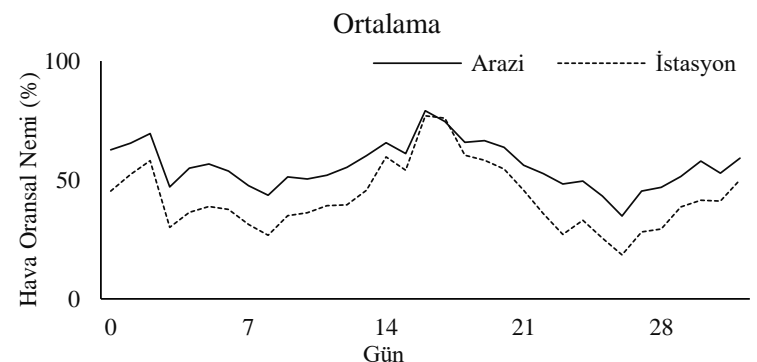

(b)

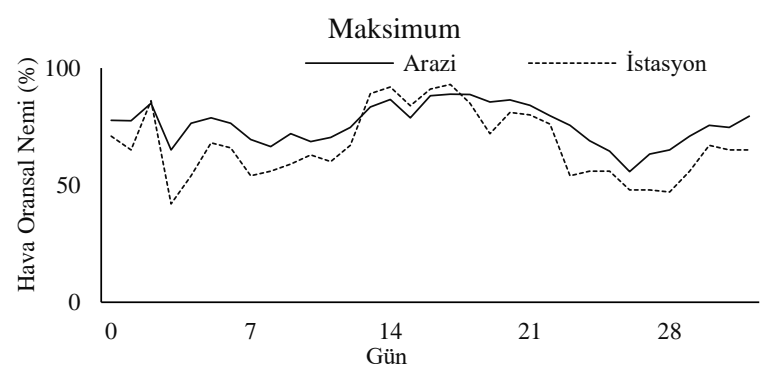

(d)

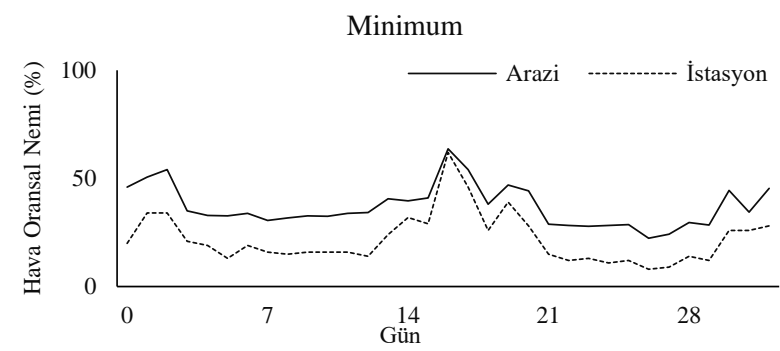

(f)

Şekil 3. Günlük değerler, (a) ortalama sıcaklık, (b) ortalama oransal nem, (c) maksimum sıcaklık, (d) maksimum oransal nem, (e) minimum sıcaklık, (f) minimum oransal nem. 
Tablo 1'de verilen değerler arasındaki farkın önemli olup olmadığı belirlenmesi için yapılan T testine göre, günlük sıcaklık ortalama değerler arasındaki fark önemsiz bulunmasına rağmen $(\mathrm{P}>0.05)$, minimum ve maksimum değerler arasındaki fark önemli bulunmuştur $(\mathrm{P}<0.05)$. Günlük oransal nem değerlerinde ise ortalama, maksimum ve minimum değerlerin tümündeki fark önemli bulunmuştur $(\mathrm{P}<0.05)$.

Çalışmanın ikinci bölümünde ise Merkez Meteoroloji İstasyonu verileri ile Havalimanı Meteoroloji İstasyonu verileri karşılaştırılmıştır. Şekil 4'de günlük ortalama sıcaklık değerleri verilmiştir.

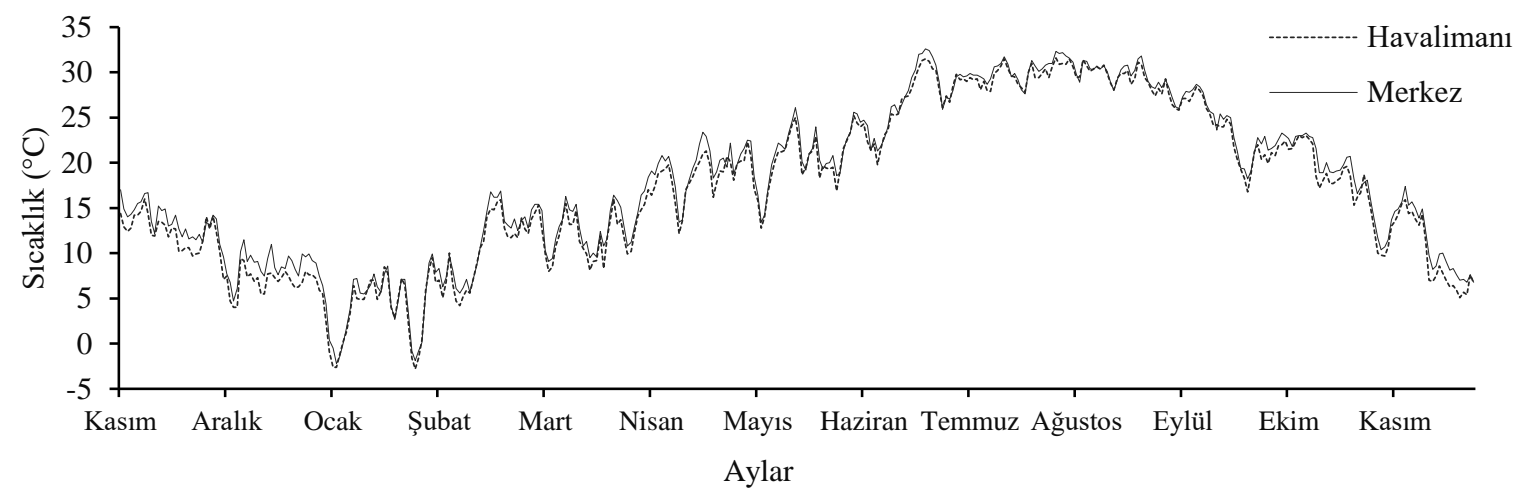

Şekil 4. Kahramanmaraş Merkez ve Havalimanı Meteoroloji İstasyonu 2015 yılı günlük ortalama sıcaklıklar

Şekil 4 incelendiğinde genel olarak her iki istasyon verilerinin örtüştügü ancak Kasım ve Aralık aylarında Merkez Meteoroloji İstasyon değerlerinin daha yüksek olduğu görülmektedir. Veriler arasındaki farklılığın daha net anlaşılması için istatistiksel analiz yapılmıştır. Veriler arasındaki ortalama mutlak hata (MAE) $0.94^{\circ} \mathrm{C}$, mutlak hata kareler ortalaması (MSE) $1.34{ }^{\circ} \mathrm{C}$, mutlak hata kareler ortalaması karekökü (RMSE) $1.16{ }^{\circ} \mathrm{C}$ ve oransal mutlak hata ortalaması (MAPE) \%7.79 olarak bulunmuştur. T testine göre, ortalamalar arasındaki farkın anlamlı olmadığı bulunmuştur $(\mathrm{P}>0.05)$. Tüm veriler üzerinde yapılan analizden ortalamalar arasında anlamlı bir fark olmadiğı sonucuna varılmasina rağmen, grafik incelendiğinde özellikle Kasım ve Aralık aylarındaki verilerin arasında anlamlı bir farklılık olabileceği görülmektedir. Bu sebeple aynı analizler her ay için tekrarlanmıştır. Analiz sonuçları Tablo 2'de verilmiştir.

Tablo 2. Kahramanmaraş Merkez ve Havalimanı Meteoroloji İstasyonu 2015 yılı günlük ortalama sıcaklıkları arasındaki istatistiksel ilişkiler

\begin{tabular}{lccccc}
\hline Aylar & $\begin{array}{c}\text { MAE } \\
\left({ }^{\circ} \mathbf{C}\right)\end{array}$ & $\begin{array}{c}\text { MSE } \\
\left({ }^{\circ} \mathbf{C}\right)\end{array}$ & $\begin{array}{c}\text { RMSE } \\
\left({ }^{\circ} \mathbf{C}\right)\end{array}$ & $\begin{array}{c}\text { MAPE } \\
(\%)\end{array}$ & $\begin{array}{c}\text { T-testi } \\
(\mathbf{P})\end{array}$ \\
\hline Kasım & 1.32 & 2.24 & 1.50 & 11.04 & 0.004 \\
Aralık & 1.79 & 3.66 & 1.91 & 28.90 & 0.000 \\
Ocak & 0.66 & 0.71 & 0.84 & 2.33 & 0.620 \\
Şubat & 0.92 & 1.09 & 1.05 & 10.90 & 0.384 \\
Mart & 0.97 & 1.34 & 1.16 & 8.80 & 0.103 \\
Nisan & 1.28 & 2.03 & 1.43 & 7.15 & 0.049 \\
Mayıs & 0.78 & 0.90 & 0.95 & 4.00 & 0.336 \\
Haziran & 0.67 & 0.70 & 0.83 & 2.57 & 0.497 \\
Temmuz & 0.55 & 0.44 & 0.67 & 1.86 & 0.082 \\
Ağustos & 0.48 & 0.36 & 0.60 & 1.63 & 0.173 \\
Eylül & 0.70 & 0.73 & 0.85 & 3.09 & 0.451 \\
Ekim & 1.00 & 1.49 & 1.22 & 5.39 & 0.119 \\
\hline
\end{tabular}

Tablo 2'deki veriler incelendiğinde tüm aylar için sıcaklık ortalamaları arasında farklılık olduğu, bu farkın en düşük Ağustos ayında en yüksek Aralık ayında olduğu görülmektedir. İstatistiksel olarak incelendiğinde ise tüm aylar için sicaklık farklılığı olmasına rağmen sadece Kasım, Aralık ve Nisan 
aylarındaki ortalama sıcaklıklar arasındaki fark anlamlı bulunmuştur $(\mathrm{P}<0.05)$.

Şekil 5'de iki farklı istasyon için günlük maksimum sıcaklık değerleri verilmiştir. Şekil incelendiğinde genel olarak verilerin örtüştüğü görülmektedir.
Yapılan istatistik analiz günlük maksimum sıcaklık ortalamaları arasındaki farklılığın önemli olmadığını yani her iki istasyondan ölçülen maksimum sıcaklıkların aynı kabul edilebileceğini göstermektedir $(\mathrm{P}>0.05)$.

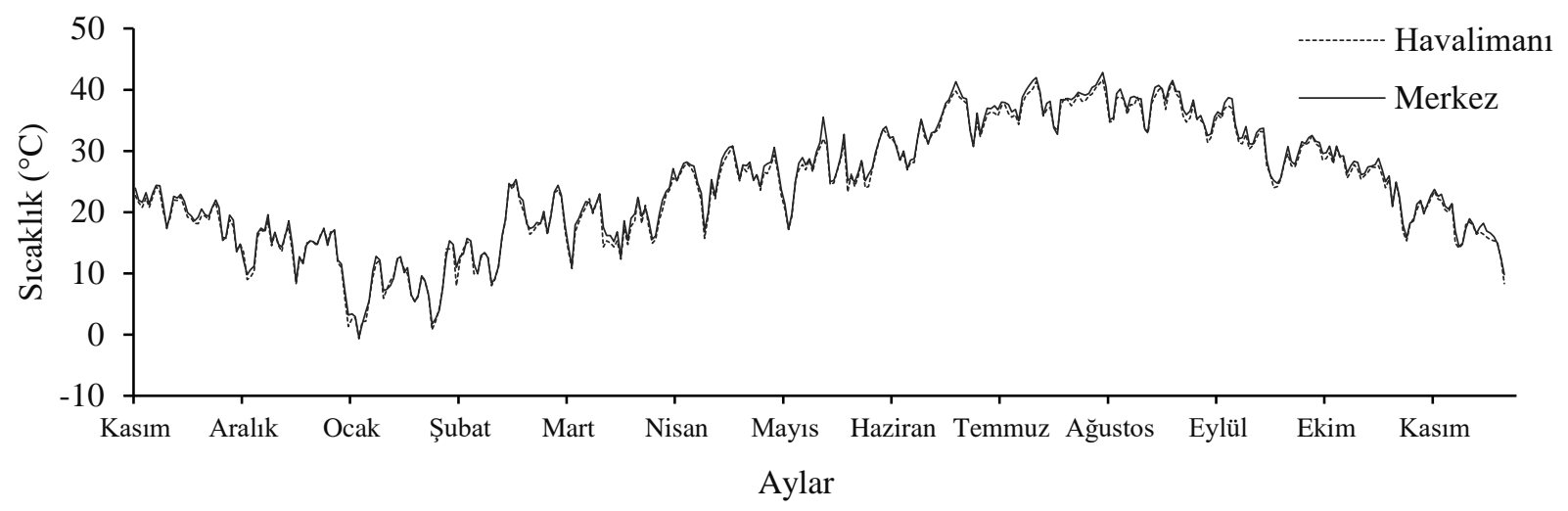

Şekil 5. Kahramanmaraş Merkez ve Havalimanı Meteoroloji İstasyonu 2015 yılı günlük maksimum sıcaklıklar

Şekil 6’da iki istasyon için günlük minimum sıcaklık değerleri verilmiştir. Şekil incelendiğinde genel olarak veriler arasında bir farklılığın olduğu, Havalimanı Meteoroloji İstasyonu minimum sicaklık değerlerinin
Merkez Meteoroloji İstasyonu değerlerinden daha düşük olduğu görülmektedir. Farklılık istatistiksel olarak analiz edildiğinde MAE 2.37, MSE 7.27, RMSE 2.70 ve MAPE 18.99 olarak bulunmuştur. Minimum sıcaklık ortalamaları arasındaki farklılık istatistiksel olarak anlamlı bulunmuştur $(\mathrm{P}<0.001)$.

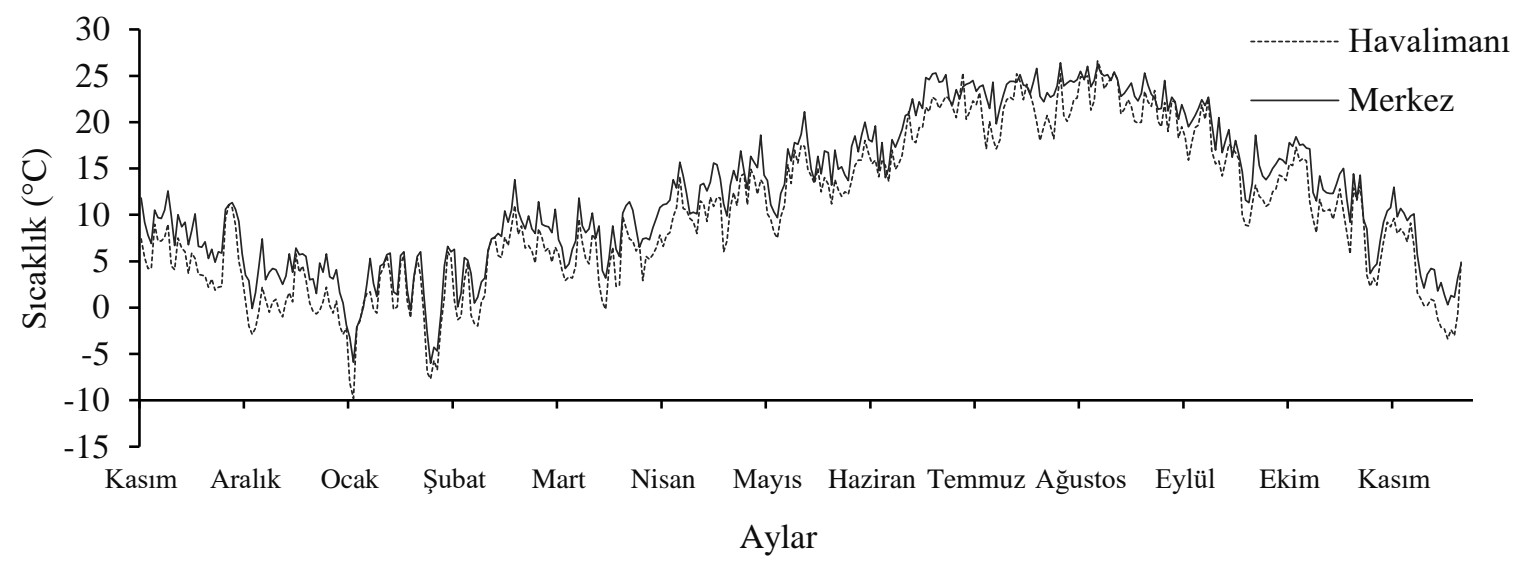

Şekil 6. Kahramanmaraş Merkez ve Havalimanı Meteoroloji İstasyonu 2015 yılı günlük minimum sıcaklıklar

Şekil 7'de ise iki istasyon için günlük ortalama oransal nem değerleri verilmiştir. Şekil incelendiğinde veriler arasında farklılık olduğu görülmektedir. İstatistiksel olarak da değerler arasında farklılık olduğu yapılan T testi ile doğrulanmıştır $(\mathrm{P}<0.001)$. Tek yönlü ANOVA testi ile de bu farklılığın anlamlı olduğu doğrulanmıştır $(\mathrm{P}<0.001)$. Ayrıca MAE 7.41, MSE 74.70, RMSE 8.64 ve MAPE 14.43 olarak bulunmuştur. 


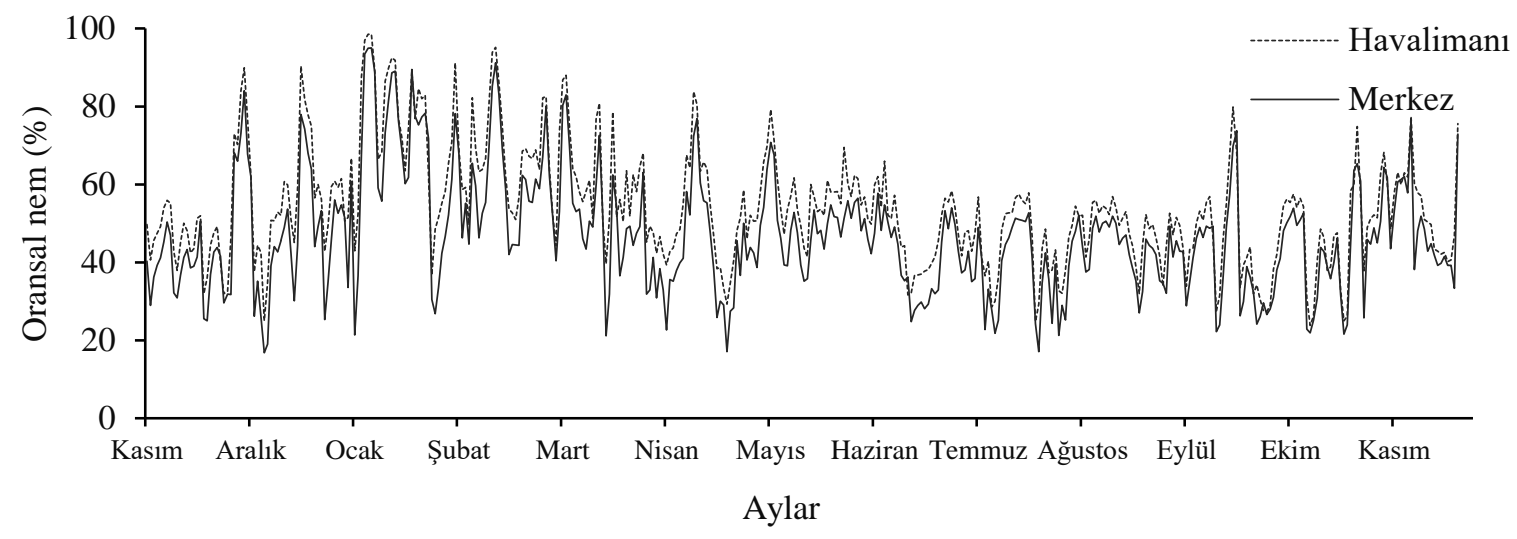

Şekil 7. Kahramanmaraş Merkez ve Havalimanı Meteoroloji İstasyonu 2015 yılı günlük ortalama oransal nem

Şekil 8'de istasyonlar için günlük maksimum oransal nem değerleri verilmiştir. Şekil incelendiğinde Havalimanı Meteoroloji İstasyonu değerlerinin Merkez Meteoroloji İstasyonundan daha yüksek seyrettiği görülmektedir. İstatistiksel olarak da değerler arasında farklılık olduğu yapılan $\mathrm{T}$ testi ile doğrulanmıştır $(\mathrm{P}<0.001)$. Tek yönlü ANOVA testi de aynı şekilde bu farklılığın anlamlı olduğu göstermiştir $(\mathrm{P}<0.001)$. Ayrica MAE 9.66, MSE 137.66, RMSE 11.73 ve MAPE 12.80 olarak bulunmuştur.

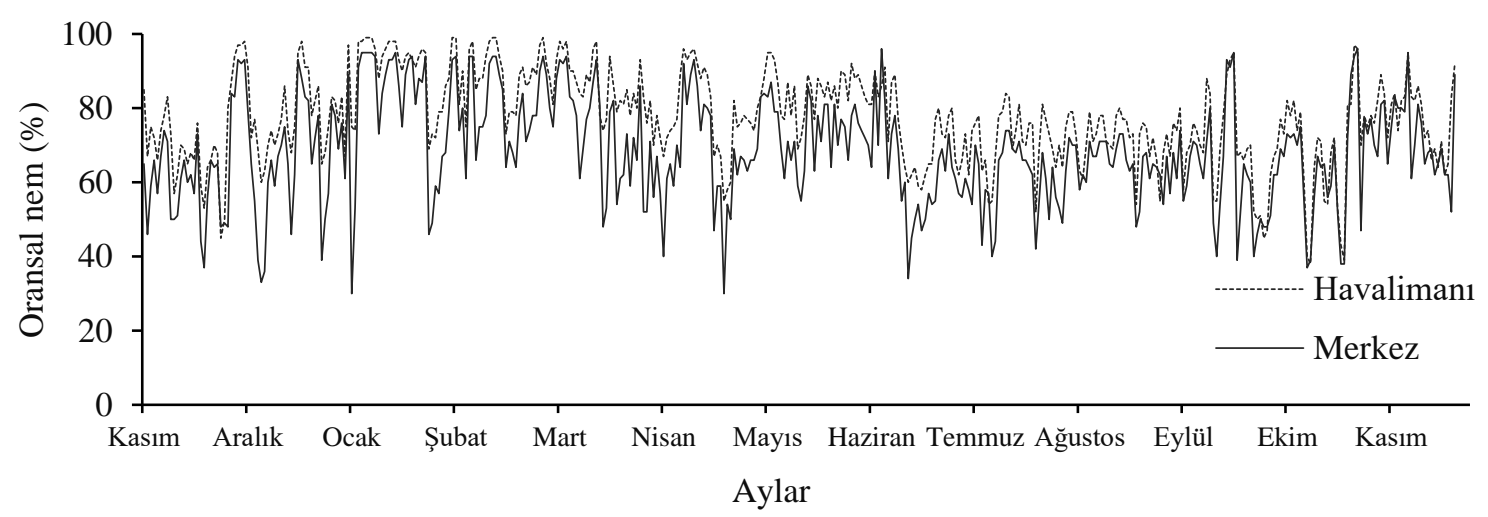

Şekil 8. Kahramanmaraş Merkez ve Havalimanı Meteoroloji İstasyonu 2015 yılı günlük maksimum oransal nem

Şekil 9'da her iki istasyona ait günlük minimum oransal nem değerleri verilmiştir. Şekil incelendiğinde günlük minimum oransal nem değerleri arasında farklılık olduğu, bu farklılı̆̆ın özellikle oransal nemin düşük olduğu dönemlerde daha fazla olduğu görülmektedir. İstatistiksel olarak da her iki istasyon değerleri arasında farklılık olduğu ve bu farklılığın anlamlı olduğu bulunmuştur $(\mathrm{P}<0.001)$. Bu veriler için MAE 5.96, MSE 49.76, RMSE 7.05 ve MAPE 21.56 olarak hesaplanmıştır. 


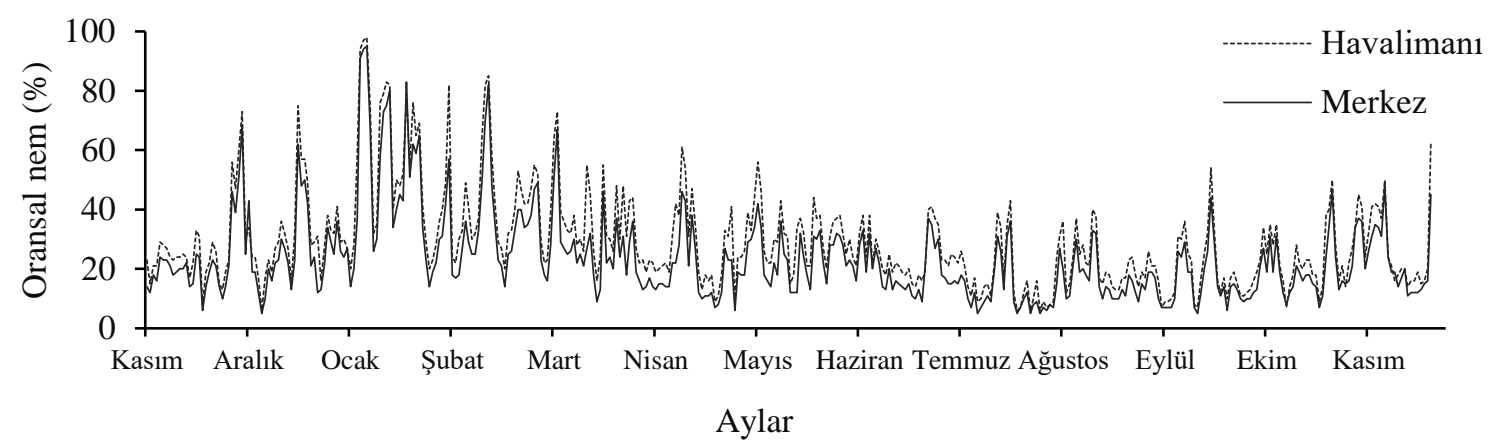

Şekil 9. Kahramanmaraş Merkez ve Havalimanı Meteoroloji İstasyonu 2015 yılı günlük minimum oransal nem

Şekil 10'da her iki istasyonda kaydedilen günlük ortalama rüzgâr hızı değerleri verilmiştir. Şekle göre tüm aylar için ortalama rüzgâr hızları arasında farklılık belirgin bir şekilde görülmektedir. Özellikle yaz aylarında Havalimanı Meteoroloji İstasyonu verileri ile Merkez Meteoroloji İstasyonu verileri arasındaki fark artmıştır. İstatistiksel olarak da bu farklılığın anlamlı olduğu görülmüştür $(\mathrm{P}<0.001)$. Ayrıca bu veriler için MAE 2.66, MSE 8.61, RMSE 2.93 ve MAPE 72.59 olarak hesaplanmıştır.

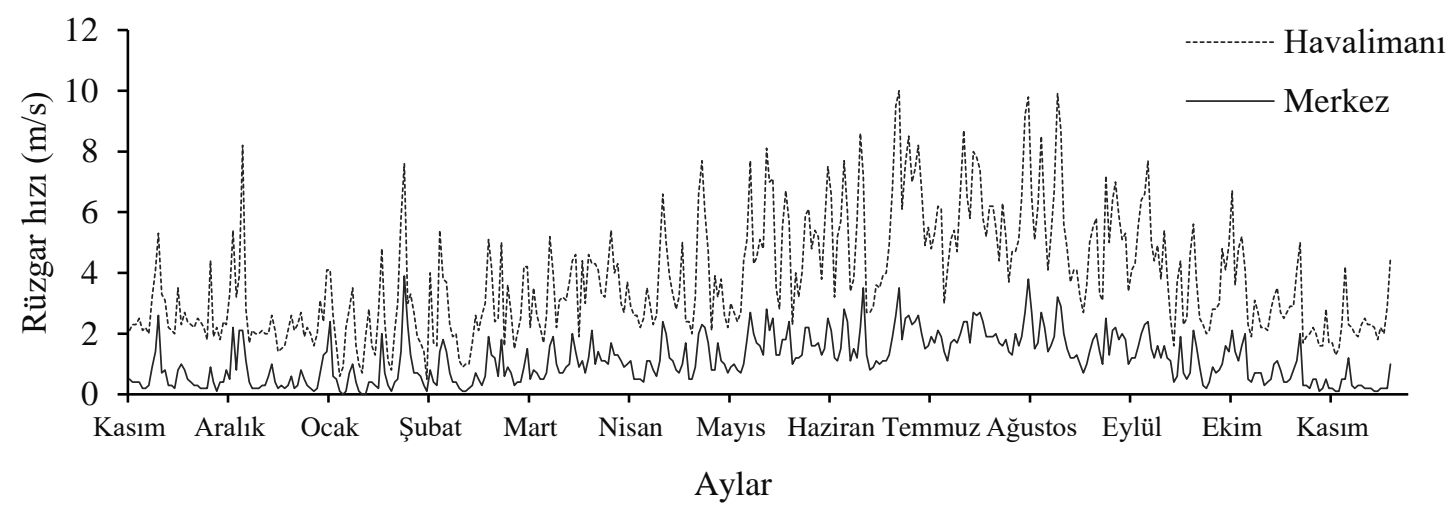

Şekil 10. Kahramanmaraş Merkez ve Havalimanı Meteoroloji İstasyonu 2015 yılı günlük ortalama rüzgâr hızı

\section{SONUÇ}

Hayvan barınaklarının iklimlendirilmesi ve projelendirilmesi, sera yapilarının isitma sistemlerinin projelenmesi, tarımsal yapıların kurulum yerinin seçimi, bitki büyüme modeli çalışmaları, sulama programlarının yapılması, hidrolojik yapıları planlanması ve projelendirilmesi gibi birçok çalışmada iklim verileri temel parametre olarak kullanılmaktadır. $\mathrm{Bu}$ sebeplerle, yapılan hesaplamalarda doğru sonuç elde edilmesi veya daha doğru tahmin yaplabilmesi, kullanılan iklim verilerine bağlıdır.

Çalışmada elde edilen bulgular, tarımsal faaliyetlerin yürütüldüğü ovadaki iklim parametrelerinin meteorolojik rasatların yapıldığı bölgenin ikliminden farklı olduğunu göstermektedir. Bu farklılık günlük sıcaklık ortalamaları için Kasım, Aralık ve Nisan aylarında belirgin bir şekilde görülmektedir. Günlük maksimum sıcaklıklar dışında, günlük minimum sıcaklık, ortalama oransal nem, maksimum oransal nem, minimum oransal nem ve rüzgâr hızı içinde her iki bölgede ölçülen değerlerin birbirinden farklı olduğu bulunmuştur.
Kahramanmaraş tarımsal arazi varlı̆̆ bakımından Akdeniz bölgesinde Adana'dan sonra ikinci surada yer almaktadır (TUIK, 2016). Şehrin güneyindeki tarım arazileri güneydoğuda Pazarcık, güneyde ise Türkoğlu ve Nurdağı'na kadar uzanmaktadır. Kahramanmaraş'ta "Maraş Ovası" olarak tabir edilen bu bölge içerisinde bulunan Havaliman Meteoroloji İstasyonuna ait iklim verileri ile şehir merkezinde bulunan Merkez Meteoroloji İstasyonu iklim verileri arasında istatistiksel olarak farklılıklar olduğu görülmektedir. Bu nedenle tarımsal faaliyetlerin yoğun olarak yapıldığı ova ile aynı coğrafi özelliklere sahip olan Havalimanı Meteoroloji İstasyonu verilerinin kullanımı daha uygun olabilir.

Elde edilen bulgular, özellikle maksimum ve minimum iklim değerleri kullanılarak yapılan hesaplamalarda, verilerin tarımsal faaliyetin yürütüldüğü ya da yakınındaki yerden alınmasının veya benzer coğrafi ve iklimsel özelliğe sahip yerlerden temin edilerek, istatistiksel enterpolasyon yöntemleri ile çalışma yapılacak alana uyarlanmasının önemli olduğunu göstermektedir. 


\section{KAYNAKLAR}

Apaydin H, Sonmez FK, Yildirim YE 2004. Spatial interpolation techniques for climate data in the GAP region in Turkey. Climate Research, 28(1), 31-40.

Bellocchi G, Rivington M, Donatelli M, Matthews K, Bellocchi G, Rivington M, Donatelli M, Matthews K 2010. Validation of biophysical models : issues and methodologies . A review. 30, 109-130. doi: 10.1051/agro/2009001

Bonhomme R 2000. Bases and limits to using 'degree day' units. European Journal of Agronomy, 13, 1-10. doi: 10.1016/S1161-0301(00)00058-7

Dikmen S, Cole JB, Null DJ, Hansen PJ 2013. Genomewide association mapping for identification of quantitative trait loci for rectal temperature during heat stress in Holstein cattle. Plos One, 8(7), e69202.

Fisher DK, Sui R 2013. An inexpensive open-source ultrasonic sensing system for monitoring liquid levels. Agricultural Engineering International: CIGR Journal, $15,328-334$.

Fodor Nn, Kovacs GzJ 2005. Sensitivity of crop models to the inaccuracy of meteorological observations. Physics and Chemistry of the Earth, 30, 53-57. doi: 10.1016/j.pce.2004.08.020

Gallagher M. B, Sandhu S, Kimsey R. 2010. Variation in developmental time for geographically distinct populations of the common green bottle fly, Lucilia sericata (Meigen). Journal of Forensic Sciences, 55(2), 438-442.

Gubbi J, Buyya R, Marusic S, Palaniswami M 2013. Internet of Things (IoT): A vision, architectural elements, and future directions. Future Generation Computer Systems, 29, 1645-1660. doi: 10.1016/j.future.2013.01.010

He H, Yang L, Fan L, Zhao L, Wu H, Yang J, Li C 2012. The effect of intercropping of maize and soybean on microclimate. Computer and Computing Technologies in Agriculture V, 257-263.

Jamieson PD, Brooking IR, Porter JR, Wilson DR 1995. Prediction of leaf appearance in wheat: a question of temperature. Field Crops Research, 41(1), 35-44. doi: http://dx.doi.org/10.1016/0378-4290(94)00102-I

Johansson E, Berglund S, Lindborg T, Petrone J, Van As D, Gustafsson LG, Näslund JO, Laudon H 2015. Hydrological and meteorological investigations in a periglacial lake catchment near Kangerlussuaq, west Greenland-presentation of a new multi-parameter data set. Earth System Science Data, 7(1), 93-108.

Kim KS, Yoo B 2015. Comparison of Regional Climate Scenario Data by a Spatial Resolution for the Impact Assessment of the Uncertainty Associated with Meteorological Inputs Data on. 2015, 249-255. doi: 10.1007/s12892-015-0115-8
Los, S, Pollack N, Parris M, Collatz G, Tucker C, Sellers P, Malmström C, DeFries R, Bounoua L, Dazlich D 2000. A global 9-yr biophysical land surface dataset from NOAA AVHRR data. Journal of Hydrometeorology, 1(2), 183-199.

Mearns LO, Easterling W, Hays C, Marx D 2001. Comparison of Agricultural Impacts of Climate Change Calculated from High and Low Resolution Climate Change Scenarios: Part 1. The Uncertainty Due to Spatial Scale. Climatic Change, 51, 131-172. doi: 10.1023/A:1012297314857

Mesas-Carrascosa FJ, Verdú Santano D, Meroño JE, Sánchez de la Orden M, García-Ferrer A 2015. Open source hardware to monitor environmental parameters in precision agriculture. Biosystems Engineering, 137, 73-83. doi: 10.1016/j.biosystemseng.2015.07.005

Monestiez P, Courault D, Allard D, Ruget F, Ruget ËO 2001. Spatial interpolation of air temperature using environmental context: Application to a crop model. Environmental and Ecological Statistics, 8, 297-309. doi: 10.1023/A:1012726317935

Monteith JL 1965. Evaporation and environment. Paper presented at the Symp. Soc. Exp. Biol.

Moorhead JE, Gowda, P. H., Marek GW, Porter, DO, Marek TH 2016. Spatial Uniformity in Sensitivity Coefficient of Reference Et in the Texas High Plains. Applied Engineering in Agriculture, 32(2), 263-269.

Mu Q, Heinsch FA, Zhao M, Running SW 2007. Development of a global evapotranspiration algorithm based on MODIS and global meteorology data. Remote Sensing of Environment, 111(4), 519-536. doi: http://doi.org/10.1016/j.rse.2007.04.015

Romanovsky V, Drozdov D, Oberman N, Malkova G, Kholodov A, Marchenko S, Moskalenko N, Sergeev D, Ukraintseva N, Abramov A 2010. Thermal state of permafrost in Russia. Permafrost and Periglacial Processes, 21(2), 136-155.

Sethi VP, Sumathy K, Lee C, Pal DS 2013. Thermal modeling aspects of solar greenhouse microclimate control: A review on heating technologies. Solar Energy, 96, 56-82. doi: 10.1016/j.solener.2013.06.034

Swan JB, Schneider EC, Moncrief JF, Paulson WH, Peterson AE 1987. Estimating Corn Growth, Yield, and Grain Moisture from Air Growing Degree Days and Residue Cover1. Agronomy Journal, 79(1), 53-60. doi: 10.2134/agronj1987.00021962007900010012x

Tan CL, Wong NH, Jusuf SK 2013. Outdoor mean radiant temperature estimation in the tropical urban environment. Building and Environment, 64, 118-129.

TUIK 2016. Tarım alanları. Türkiye İstatistik Kurumu.

Zhao G, Siebert S, Enders A, Rezaei EE, Yan C, Ewert F 2015. Demand for multi-scale weather data for regional crop modeling. Agricultural and Forest Meteorology, 200, 156-171. doi: 10.1016/j.agrformet.2014.09.026 